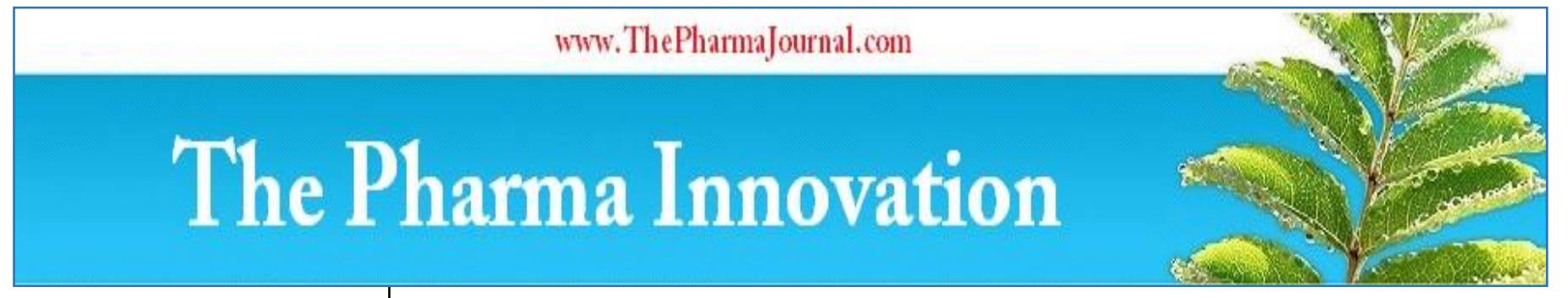

ISSN (E): 2277 - 7695

ISSN (P): 2349-8242

NAAS Rating: $\mathbf{5 . 0 3}$

TPI 2020; SP-9(7): 267-268

(C) 2020 TPI

www.thepharmajournal.com

Received: 25-05-2020

Accepted: 27-06-2020

Gireesh Kumar V

Professor, Department of

Veterinary Surgery and

Radiology, C.V.Sc, Hyderabad,

PVNR TVU, Telangana, India

Ashok Kumar Reddy GV

M.V.Sc Scholar, Dept. of

Veterinary Surgery and

Radiology, C.V.Sc, Hyderabad,

PVNR TVU, Telangana, India

Corresponding Author:

Ashok Kumar Reddy GV

M.V.Sc Scholar, Dept. of

Veterinary Surgery and

Radiology, C.V.Sc, Hyderabad,

PVNR TVU, Telangana, India

\section{Surgical management of cherry eye in a cocker spaniel $\operatorname{dog}$}

\author{
Gireesh Kumar V and Ashok Kumar Reddy GV
}

DOI: $\underline{\text { https://doi.org/10.22271/tpi.2020.v9.i7Se.5003 }}$

Abstract

A two year old intact male cocker spaniel was presented with a history of pink coloured mass on the medial side of right eye from last 10 days. After clinical examination the condition was diagnosed as prolapse of third eye lid gland. The condition was corrected by using Morgan's pocket technique. The pocketing technique does not alter the tear production and morphology of the third eyelid gland ducts.

Keywords: Cherry eye, third eyelid gland, Morgan's pocketing technique

\section{Introduction}

Prolapse of third eyelid gland is known as cherry eye. The function of third eyelid was to protect the eye and tear film distribution. Cherry eye condition was more common in dogs compared to cats and the condition may be unilateral or bilateral. Breeds especially Bulldog, Pekingese, Cocker Spaniel, Neapolitan Mastiff, Beagle and Basset Hound are more prone to the condition of cherry eye ${ }^{[2,4]}$. However the etiology of cherry eye was unclear ${ }^{[1,3]}$. The main cause of prolapse is weakening of supportive ligament that fixes the gland. The present case study reports the successful surgical correction of cherry eye using Morgan's pocketing technique.

\section{History and Diagnosis}

A two year old intact male Cocker Spaniel dog, was presented to the hospital with a history of pink coloured mass in the medial canthus of the right eye (Fig.1). This condition persisted for past 10 days and has severe irritation, epiphora. Clinical examination revealed that heart rate, respiratory rate and temperature were within normal range. On examination the condition was diagnosed as Cherry eye and the Morgan's pocketing technique was selected as option for surgical correction. Preoperative haematology and serum biochemistry parameters were evaluated and are found to be within the normal range.

\section{Surgical Procedure}

The periorbital area of right eye was prepped aseptic. The dog was premedicated with atrophine sulphate@0.04mg/kg subcutaneously and xylazine@1mg/kg and ketamine@ $10 \mathrm{mg} / \mathrm{kg}$. The anaesthesia was maintained with propofol to affect. The dog was positioned in sternal recumbency and the affected eye was flushed with normal saline. Two parallel incisions were made on either of the prolapsed gland on the bulbar and palpebral conjunctiva and the bases of the incisions were sutured in simple continuous pattern using 4-0 PGA. Anchoring on the external side of eyelid is necessary to avoid irritation of suture ends on to the cornea. After the surgical procedure the owner was advised E collar application. Gatifloxacin $0.3 \%$ eye drops were advised to instil into the eye for a period of 7 days thrice daily.

The dog was monitored for reccurence and signs of kerato-conjunctivis sicca (KCS) for period of 6 months post surgery. The dog recovered well and no reccurence was noticed in the follow up period (Fig.2).

\section{Discussion}

The resection of third eyelid gland lowers tear values by $15-26 \%$ in cats and $40 \%$ in dogs. The third eyelid gland plays a major role in maintaining the tear film across the cornea and protects the cornea ${ }^{[3]}$. Removing the gland increases the risk of developing KCS (dry eye), in which the eye cannot produce enough tears to lubricate and protect the cornea ${ }^{[5,6]}$. 
The technique of surgical repositioning is easy to perform and has greater success rate and fewer complications than other treatment modalities such as conservative and excision of the prolapsed third eyelid gland ${ }^{[1]}$. The pocketing technique does not alter the tear production and morphology of the third eyelid gland ducts. As the technique is easier to perform and the advantages compared to other techniques made it suitable for surgical correction of cherry eye. The client satisfaction and overall success rate made the pocketing technique amenable for correction of prolapsed third eyelid gland.

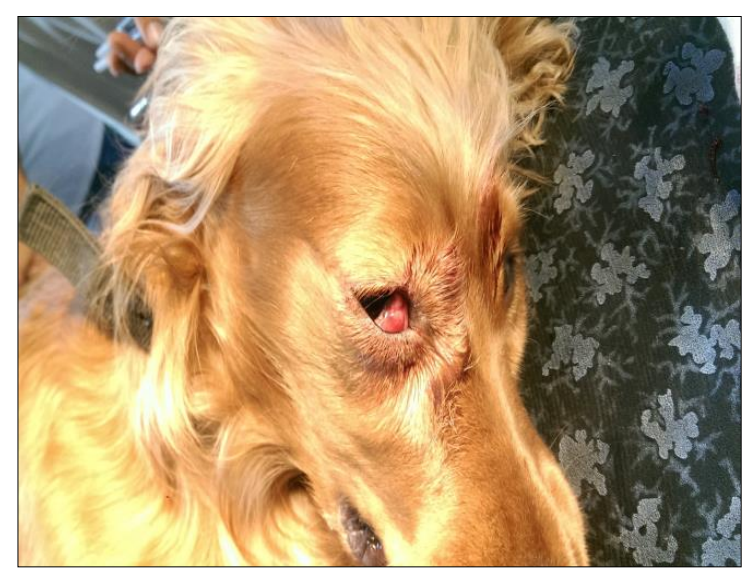

Fig 1: Prolapsed third eyelid gland in right eye.

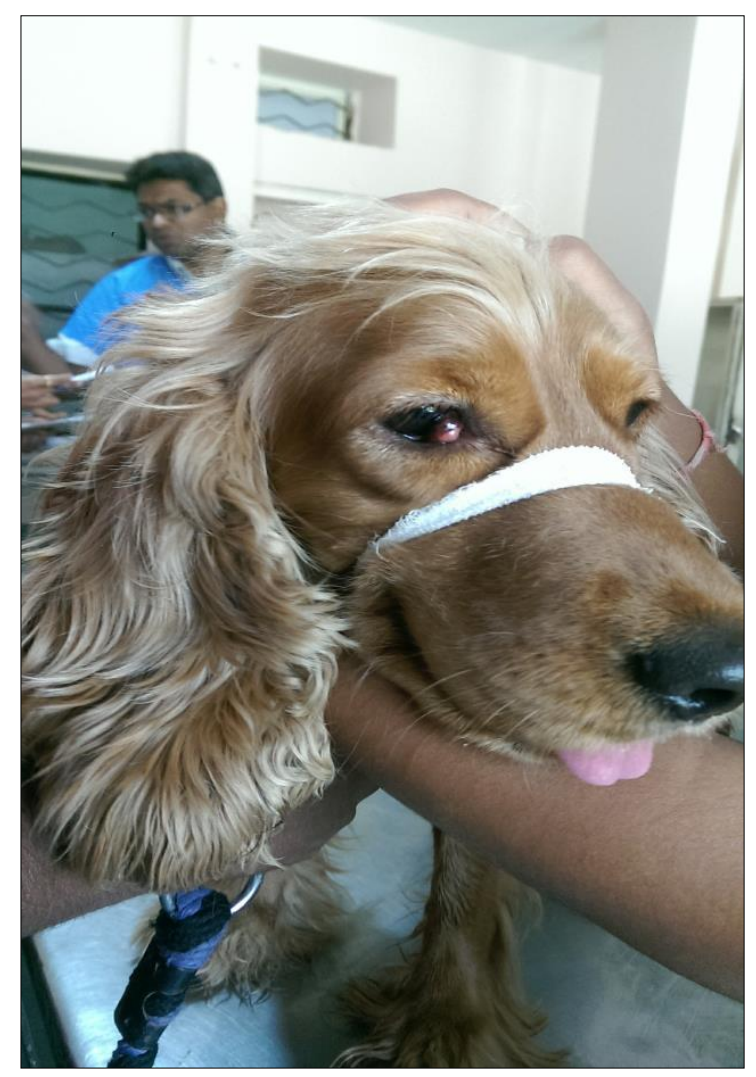

Fig 2: Surgical correction using Morgan's pocket technique.

\section{References}

1. Dugan SJ, Severin GA, Hungerford LL, Whiteley HE, Roberts SM. Clinical and histological evaluation of the prolapsed third eyelid gland in dogs. J Am. Vet. Med. Assoc. 1992; 201:1861-1867.

2. Herrera D. Surgery of the Eyelids, Proceedings of the World Small Animal Veterinary Association Mexico City, Mexico, 1-4 PMid: 16203008, 2005.
3. Martin CL. Conjunctiva and third eyelid. In: Martin, C.L., Ed. Ophthalmic Disease in Veterinary Medicine. Manson Publishing Ltd., London, 2009, 183-214.

4. Moore CP. Terceira pálpebra. In: Slatter D., Manual de cirurgia de pequenos animals, 2nd Ed., Paulo: Manole. 1998; 2:1428-1435.

5. Slatter D. Third eyelid. In: Slatter, D., Ed. Fundamentals of Veterinary Ophthalmology. 3rd ed., Saunders, Philadelphia, 2001, 229-232.

6. Wyman M. Manual of Small Animal Ophthalmology. Churchill Livingstone Inc., New York, 1986, 125-133. 